\title{
POTENTIAL OF SENTINEL-1A FOR NATION-WIDE ROUTINE UPDATES OF ACTIVE LANDSLIDE MAPS
}

\author{
M. Lazecky ${ }^{a *}$ F. Canaslan Comut ${ }^{\text {b }}$, E. Nikolaeva ${ }^{\text {, }}$, M. Bakon ${ }^{\text {d }}$, J. Papco ${ }^{\text {d }}$, A. M. Ruiz-Armenteros ${ }^{\mathrm{e}}$, Y. Qin ${ }^{\mathrm{f}}$, J. J. M. de Sousa ${ }^{\mathrm{g}}$, P. \\ Ondrejka ${ }^{\mathrm{h}}$ \\ ${ }^{a}$ IT4Innovations, VSB-TU Ostrava, Czech Republic-milan.lazecky@vsb.cz \\ ${ }^{\text {b }}$ Turkey Disaster \& Emergency Directorate (AFAD) of Denizli, Turkey - fatma.c.comut@afad.gov.tr \\ ${ }^{c}$ Ilia State University, Tbilisi, Georgia - elenanikolaeva@hotmail.com \\ ${ }^{d}$ Dept. of Theoretical Geodesy, STU Bratislava, Slovakia - matusbakon@gmail.com, juraj.papco@stuba.sk \\ ${ }^{\text {e }}$ Departamento de Ingeniería Cartográfica, Geodésica y Fotogrametría, CEAC Tierra, Universidad de Jaén, Spain - \\ amruiz@ujaen.es \\ ${ }^{\mathrm{f}}$ Lyles School of Civil Engineering, Purdue University, USA - qyuxiao@purdue.edu \\ ${ }^{g}$ UTAD, Vila Real and INESC-TEC (formerly INESC Porto), Portugal - jjsousa@utad.pt \\ ${ }^{\mathrm{h}}$ State Geological Institute of Dionýz Štúr, Slovakia - peter.ondrejka@geology.sk
}

\section{Theme Session ThS 3}

KEY WORDS: Landslide activity, Public authorities, SAR Interferometry, Landslide inventory map, Sentinel-1A

\begin{abstract}
:
Slope deformation is one of the typical geohazards that causes an extensive economic damage in mountainous regions. As such, they are usually intensively monitored by means of modern expertise commonly by national geological or emergency services. Resulting landslide susceptibility maps, or landslide inventories, offer an overview of areas affected by previously activated landslides as well as slopes known to be unstable currently. Current slope instabilities easily transform into a landslide after various triggering factors, such as an intensive rainfall or a melting snow cover. In these inventories, the majority of the existing landslide-affected slopes are marked as either stable or active, after a continuous investigative work of the experts in geology. In this paper we demonstrate the applicability of Sentinel-1A satellite SAR interferometry (InSAR) to assist by identifying slope movement activity and use the information to update national landslide inventories. This can be done reliably in cases of semi-arid regions or low vegetated slopes. We perform several analyses based on multitemporal InSAR techniques of Sentinel-1A data over selected areas prone to landslides.
\end{abstract}

\section{INTRODUCTION}

\subsection{Current practices in landslide inventory maps}

Landslides are present in all continents, and play an important role in the evolution of landscapes. They also represent a serious hazard in many areas of the world. Preparing landslide maps is important to document the extent of landslide phenomena in a region, to investigate the distribution, types, pattern, recurrence and statistics of slope failures, to determine landslide susceptibility, hazard, vulnerability and risk, and to study the evolution of landscapes dominated by mass-wasting processes. Conventional methods for the production of landslide maps rely chiefly on the visual interpretation of stereoscopic aerial photography, aided by field surveys. These methods are time consuming and resource intensive. New and emerging techniques based on satellite, airborne, and terrestrial remote sensing technologies, promise to facilitate the production of landslide maps, reducing the time and resources required for their compilation and systematic update. A concise review of the used methods for landslide inventory can be found in Guzzetti et al. (2012).

The main scopes for landslide inventory maps cover: (i) documenting the extent of landslide phenomena in areas ranging from small to large watersheds, and from region to state or nations, (ii) as a preliminary step toward landslide susceptibility, hazard, and risk assessment, (iii) the investigation of the distribution, types, and patterns of landslides in relation to morphological and geological characteristics, and (iv) to study the evolution of landscapes dominated by mass-wasting processes.

Landslide maps can be prepared using different techniques depending on the purpose of the inventory, the extent of the study area, the scale of the base maps, the scale, resolution and characteristics of the available imagery (e.g., aerial photographs, satellite images, LIDAR elevation data), the skills and experience of the investigators, and the resources available to complete the work. Landslide maps are classified by their scale and the type of mapping. Small-scale inventories $(<200.000)$ are compiled from archive studies, medium-scale $(1: 25.000$ to $1: 200.000)$ mainly from the interpretation of aerial photographs, and large-scale $(>1: 25.000)$ using both the interpretation of aerial photograhs, very high resolution satellite images or digital terrain models, and extensive field investigations.

Landslide inventory maps are produced using conventional methods like geomorphological field mapping and the visual interpretation of stereoscopic aerial photographs, and new moderm techniques. These new and recent methods include the use of very-high resolution digital elevation models (DEMs) as the obtained from LIDAR technology, and the interpretation and analysis of images from passive and active remote sensing techniques. In the case of optical images (medium and high-resolution), the techniques use panchromatic (single band), composite, false-color, pan sharpened images, and multispectral (multiple bands) images, including image classification methods and semi-automatic detection and mapping of landslides. For active remote sensing, the new

* Corresponding author 
techniques make use of synthetic aperture radar (SAR) images throught out the analysis of time series of surface deformation at specific points obtained by radar interferometric techniques. Finally, the modern approaches include the use of new tools to facilitate field mapping such a GNSS data, modern digital cameras with build-in GPS capabilities, laser distance meters, digital compasses, hand-held devices for the acquisition of data in the field assited with dedicated GIS technology.

In practice, national geological surveys usually do not periodically update their landslide inventories. Newly detected and reported landslides are mapped into the inventory using mentioned capabilities, very often with support of a high resolution DEM model, and its spatial information is connected with its database entry. The evaluation of activity of older known landslides is in many countries done based on existing concluding reports by investigating geological companies.

Landslide inventories and especially landslide maps are not necessarily present in every country. For example in Georgia, despite the known landslide hazards causing infrastructural damage and fatalities (Jibson et al., 1994; van Westen et al., 2012; Gracheva and Golyeva, 2010), a national digital landslide inventory covering the entire country was not available until 2015 (Gaprindashvili and van Westen, 2015). National scale landslide susceptibility map was generated by a Spatial Multi Criteria Evaluation method using an available (incomplete) landslide inventory from the National Environmental Agency, the Forest Management Department, and mass media. Also, supplement maps were used such as lithology, DEM, land cover, hydrology, geomorphology, precipitation and physical geography. However, this landslide susceptibility map is only an approximation and contains a high degree of uncertainty (Gaprindashvili and van Westen, 2015). To improve landslide susceptibility map, the land inventory should be improved. Until now, the main monitoring system of the mass movement is a field survey in Georgia. A huge landslide in Tbilisi from July 2015 is an indicator of the need of a remote monitoring system and experts to analyze remote sensing data that would allow to monitor and study the dynamics of landslides in Georgia. Several publications demonstrate application of remote sensing data to detect, analyze and monitor landslides for local Georgian areas (Nikolaeva et al., 2013; Nikolaeva and Walter, 2012, 2013; Elashvili et al., 2012). Landslides were detected and analyzed using various SAR data and techniques and supplemented with optical data, demonstrating the potential to use remote sensing data to detect, monitor and analyze mass movement activity. Demonstrated possibilities await their practical service.

\subsection{SAR Interferometry for landslide identification}

Satellite SAR interferometry (InSAR) has the potential to detect ground surface motion phenomena with the accuracy of a small fraction of the radar wavelength, usually from 3 (X-band) to $24 \mathrm{~cm}$ (L-band) on large areas with high spatial resolution (up to $1 \mathrm{~m}$ in the case of the new generation sensors onboard of the German TERRASAR-X and the Italian COSMO-SkyMed). Thanks to its capability in detecting millimeter level displacements over long periods and large areas, multi-temporal interferometric (MT-InSAR) techniques analysis can be considered complementary to conventional geological and geomorphological studies in landslide detection and monitoring. Indeed the landslide mechanism is seated below the surface but for observing the creeping movements of the slope surface, InSAR is evaluated as a promising remote sensing technology (Scaioni et al., 2014).

In the last years, several studies have proven MT-InSAR feasibility in landslide detection and monitoring using the whole range of wavelength, depending on the phenomena and the characteristics of the area under analysis. For instance, Vöge et al. (2015) used MT-InSAR techniques applied to C-band ASAR and ERS images to identify and map landslides in a very sensitive area located in the India Himalayan region. Xue et al. (2016) used C-band ASAR images obtained from July 2003 to March 2010 to slope monitoring in the over 3.5 million inhabitants Lanzhou city area (China). Sun et al. (2015) used ALOS L-band images acquired between January 2007 and May 2010 to conclude that Zhouqu giant landslide that caused over than 1700 fatalities in 2010, shown instabilities before the event and Novellino et al. (2015) present a MT-InSAR analysis to monitor landslide in Costa Della Gaveta (Italy) using TerraSAR-X images acquired between February 2010 and April 2011. Macciotta et al. (2016) proposed an early warning system for a very slow landslide displacement monitoring by integrating MT-InSAR techniques with a set of in situ deployed techniques/equipment. Other authors focus also into the field of InSAR application for landslide early warning and conclude about a possibility of monitoring slow creeping slope movements and their dynamics while for a specific landslide, a high acquisition frequency of ground-based SAR instrument is more suitable (Del Ventisette et al., 2015).

Within current SAR systems, the main limitations lie in the orientation and a vegetation coverage of the observed slopes. The ascending and descending tracks offer observation of slope movements that are not oriented towards $\mathrm{N}$ or S. Modern techniques such as multiple-aperture InSAR (MAI) may overcome this limitation but deal with other specific issues (Jung et al., 2013). The vegetation coverage causes temporal decorrelation and thus inability to distinguish between local slope and a vegetation movement. Low frequency SAR systems can overcome this limitation to some extent (e.g. L-band SAR satellites such as Japanese ALOS-2) by its canopy penetrating abilities. Instruments using shorter wavelength overcome the decorrelation due to vegetation growth by a higher revisit time. European Sentinel-1A (S-1A) revisits a track every 12 days.

\subsection{New possibilities using Sentinel-1 interferometry}

Comparing with other C-band satellites in the past (for example, Envisat) or at current (for example, Radarsat-2), S-1A advantages come from three aspects: wide range coverage, high spatial resolution and shorter revisit time. Specifically, S-1A takes the wide swath (IW) mode as its default scanning mode. The IW mode allows the satellite to scan up to $240 \mathrm{~km}$ in the range direction. Meanwhile, by using a larger bandwidth (of $56.50-42.80 \mathrm{MHz}$ ) comparing with the previous generation of ESA satellites (ERS and Envisat), S-1A IW mode is able to maintain a finer resolution of 5 meters in range and 20 meters in azimuth direction. In addition to the wide area coverage and high scanning resolution, S-1A has a 12-days revisit time. Comparing with the 35-day-Envisat and 24-day-Radarsat-2, S-1A greatly improved the temporal resolution for interferometry applications. Furthermore, with the launch of its twin satellite S-1B scheduled in April 2016, the revisit time between the twins will be decreased to 6 days. Last but not the least, Sentinel datasets are free to public, which gives the science community more opportunities to explore.

All these advantages of S-1A data provide a lot of new possibilities for real time monitoring work with S-1A interferograms. To start with, the wide coverage allows monitoring of wide range earth surface dynamic movements, such as earthquakes, volcano activities, glacier drifts and so on. In the second place, the fine temporal resolution allows interferograms to keep a close track of ground motions with a high temporal correlation. Nevertheless, with its high spatial resolution S-1A is also capable of monitoring smaller scale 
targets, man-made infrastructures, such as dams, buildings and airports. The fast delivery of Sentinel data to the public made it possible to do real time monitoring and publish useful information at first time. A number of projects already demonstrated the potential of S-1A interferometry, including for instance application to volcano monitoring (González et al., 2015) or observation of effects of the earthquake in Chile (Grandin et al., 2016), South Napa (Polcari et al., 2014) or Pishan in China (Wen et al., 2016).

\section{INHABITED SLOPES}

The strategy of applying common multitemporal InSAR techniques such as Permanent/Persistent Scatterers (PS) InSAR yields in very reliable results and possibility to obtain dynamics of the movement within estimated data time series. However the reliability depends on the presence of temporally coherent scatterers, such as buildings or at least bare rocks. The high revisit time of S-1A allows frequent measurements that captures PS dynamics in a higher temporal detail than using e.g. Envisat ASAR system and thus may evaluate also movements with a higher velocity rate.

\subsection{Babadag, Turkey}

Babadag is a small town of Turkey and $30 \mathrm{~km}$ away from the centre of the city Denizli in Aegean region (Lat: $37^{\circ} 48^{\prime} 38.37^{\prime \prime N}$, Lon: $\left.28^{\circ} 51^{\prime} 33.38^{\prime \prime} \mathrm{E}\right)$ which has been seriously affected by a landslide phenomena since last 60 years. The Babadag landslide has been evaluated from Envisat in a previous work (Lazecký et al., 2015). Because of low number of images and high rate of decorrelation in the area (also due to fast movements), the result could be achieved only using an MT-InSAR methodology using only coherent spatially filtered interferograms rather than the whole time series in the PS algorithm. In this case, Quasi-PS technique was used (Perissin et al., 2007). In case of processing based on S-1A, a higher rate of deformation could be captured reliably due to a higher revisit time. With only 12 images used from $10^{\text {th }}$ September 2015 $20^{\text {th }}$ March 2016, the PS processing allowed detection of movement in the rate of almost $100 \mathrm{~mm} /$ year in the satellite line-of-sight (LOS). The result is shown in Fig. 1. The technology reveals a continuous movement of the slope in a relatively high rate. Babadag village has been evacuated already in 2006 (Canaslan-Comut et al., 2015a).

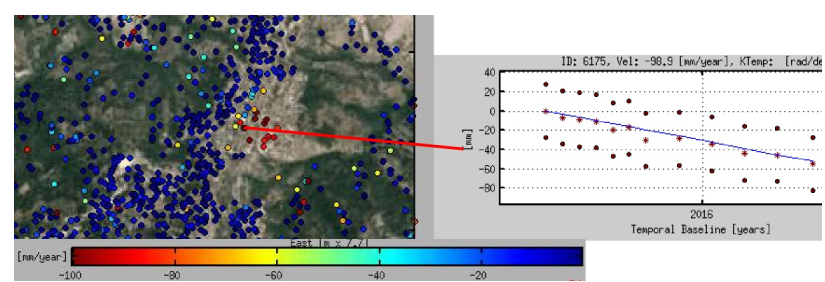

Figure 1. A high rate of landslide movement detected by Sentinel-1A PS InSAR over Babadag village, Turkey.

\subsection{Prievidza, Slovakia}

The region of Prievidza, in the central part of Slovakia, is affected by various types of slope failures, especially landslides. The 2012-2013 reactivation of slope deformations in Hradec and Velka Lehotka suburbs of the Prievidza city (Slovakia) caused serious damage to the local infrastructure and buildings. The assessment of the physical activity in these locations of active landslides becomes crucial after attaining emergency conditions in June 2013. Current monitoring techniques were focused in observation of the groundwater level and precise inclinometer measurements. While the method of precise inclinometer provides information on the deformation evolution directly on the shear zone over the points within surroundings of monitored objects, the InSAR observations enable to assess the deformation phenomena fully across the sliding areas.

In the area of $4.5 \times 4 \mathrm{~km}\left(18 \mathrm{~km}^{2}\right) 391$ and 425 radar scattering targets have been identified in ascending and descending track, respectively. The multivariate outlier removal procedure (Bakon et al., 2016) have been applied in order to preserve spatial and statistical dependency among low coherent observations, preserving 122 and 39 targets that would be discarded by the standard thresholding with 0.7 on ensemble coherence value. The deformation maps (Fig. 2) are the result of PS InSAR analysis of $52 \mathrm{~S}-1 \mathrm{~A}$ images acquired over ascending 175 (29) and descending track 175 (23) in the period from 10/2014 to 11/2015. Both ascending and descending velocities were referenced to the same reference point located in the most stable northern part of the Hradec village, that rest exclusively upon the jointing edges of the landslide, on the block formed by lava flows of pyroxene andesites.
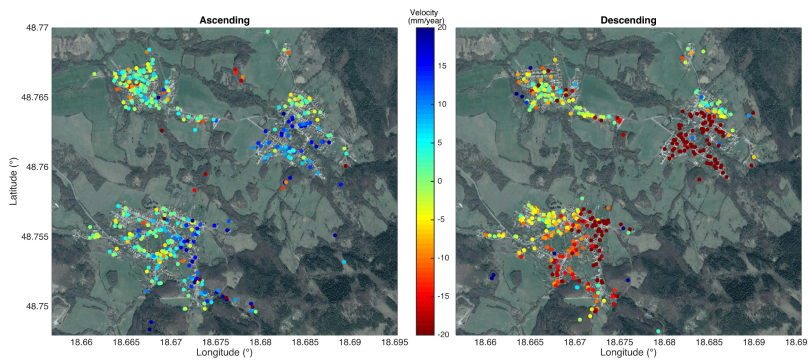

Figure 2. Deformation maps with mean LOS velocities obtained by PS InSAR analysis of Sentinel-1 radar imagery from ascending and descending track.

Thanks to availability of both sensing geometries, a decomposition to vertical and one horizontal component in descending azimuth look direction is possible. The strategy for 3D decomposition holds for: i) subdivision of the area into the regular grid of $50 \times 50 \mathrm{~m}$; ii) obtaining geographical coordinates for the centres of each grid cell; iii) computing mean LOS velocities for the cell centres using all the scatterers allocated within the same cell and separately for ascending and descending track; iv) computing vertical and horizontal displacement velocities (Fig. 3) based on (Samieie-Esfahany et al., 2009).
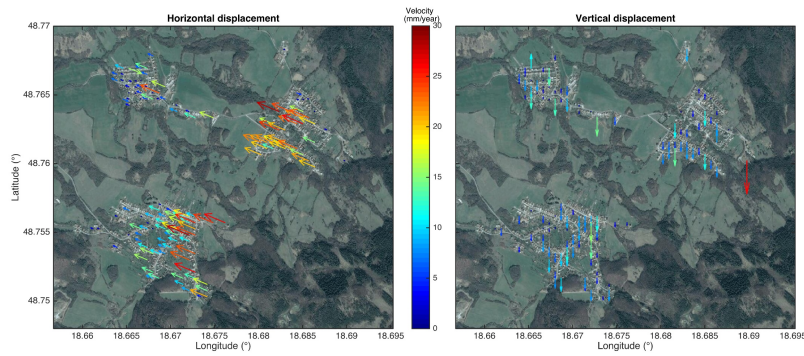

Figure 3. Horizontal (descending azimuth look direction) and vertical (up and down direction) displacement velocities in centres of the regular grid $(50 \times 50 \mathrm{~m})$.

The areas affected by strong deformation process are evident over vast majority of Hradec and Velka Lehotka suburbs (Fig. $1,3)$. The active parts of the area are corresponding mainly to the landslide deluvia and they are in agreement with boundaries of active landslides that were geologically mapped by (Malgot et al., 1983). Since the deformation process detected in ascending track (towards the satellite) occurs in opposite 
direction in comparison to descending track (away from the satellite), the real movement vector of the monitored area appears to have significant transition in horizontal direction.

It is necessarily to be noted that while exploiting former ERS and ENVISAT missions, this deformation processes remained unnoticed due to rapid changes that were undetectable utilising revisit periods of 35 days (and more). Since the deformation phenomena is persistent over recent days and the area is under vital monitoring efforts, this underlines the operational capability of S-1A observations for routine updates of active landslide maps.

\section{NATURAL SLOPES}

Majority of landslide threats are at slopes covered by vegetation in variable density and very often without any artificial object that would allow application of PS InSAR. While some other MT-InSAR techniques are widely used, their success depends mostly on amount of vegetation cover and the velocity of slope movement. A family of techniques using connections of short temporal and geometrical baselines is often called Small Baselines MT-InSAR (SB). The success of SB lies in that only interferograms with short temporal baselines are applied for the processing. This way the vegetation has a smaller effect, but thus only moderately moving slopes can be detected. With increasing temporal baseline that would reliably distinguish slower slope movements, however, the temporal decorrelation due to vegetation rapidly increases.

\subsection{Landslides at Sarez lake, Tajikistan}

Least-squares or another algorithm used for estimation of annual velocity of the movement from the family of SB methods usually overrates the velocity. This is probably the case of the estimated rate of a landslide at Sarez lake in Tajikistan, as computed using SB processing of $15 \mathrm{~S}-1 \mathrm{~A}$ images between $17^{\text {th }}$ March $2015-11^{\text {th }}$ March 2016. The movement is detected at one slope but the areas known to be sliding slowly are not captured or visible in the Fig. 4 due to the large scale of estimated values. The detected active landslide (red spot on the W), however, has an important qualitative information value. Though there are various projects existing for monitoring the dangerous situation around Sarez lake, there is a persisting problem with an inaccessibility of the area for insitu measurements, thus the need for remote sensing approaches (Abdullaev et al., 2011).

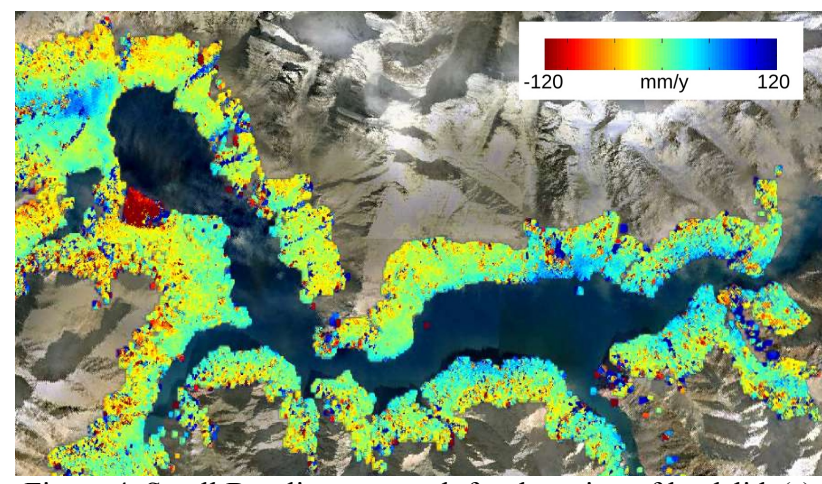

Figure 4. Small Baseline approach for detection of landslide(s) at Sarez lake, Tajikistan from S-1A data.

\subsection{Rules Reservoir, Spain}

Rules Reservoir is a reservoir in Vélez de Benaudalla, province of Granada, Andalusia, Spain. The Rules Dam is located on the river Guadalfeo, downstream from its confluence with the Izbor river, in the municipality of Vélez de Benaudalla and collects the water from the southern slopes of Sierra Nevada mountain range, from Sierra de Lújar and from La Contraviesa.

Since the region is very dry and can be classified as semi-arid, the slopes around the Rules reservoir could be observed reliably using PS InSAR technique. The detection of a landslide using Envisat ASAR data from 2002-2009 (see Fig. 5) was of a great importance since the landslide activity has not been known before. The N-323 road from the national network crosses throughout the landslide. The hillsides of the road have retaining/protective walls to retain their slip (Fig. 5 below). A continuous movement of the slope was detected also from later S-1A data. A result from PS InSAR processing using S-1A data of $10^{\text {th }}$ March $2015-28^{\text {th }}$ March 2016 is shown in Fig. 6.

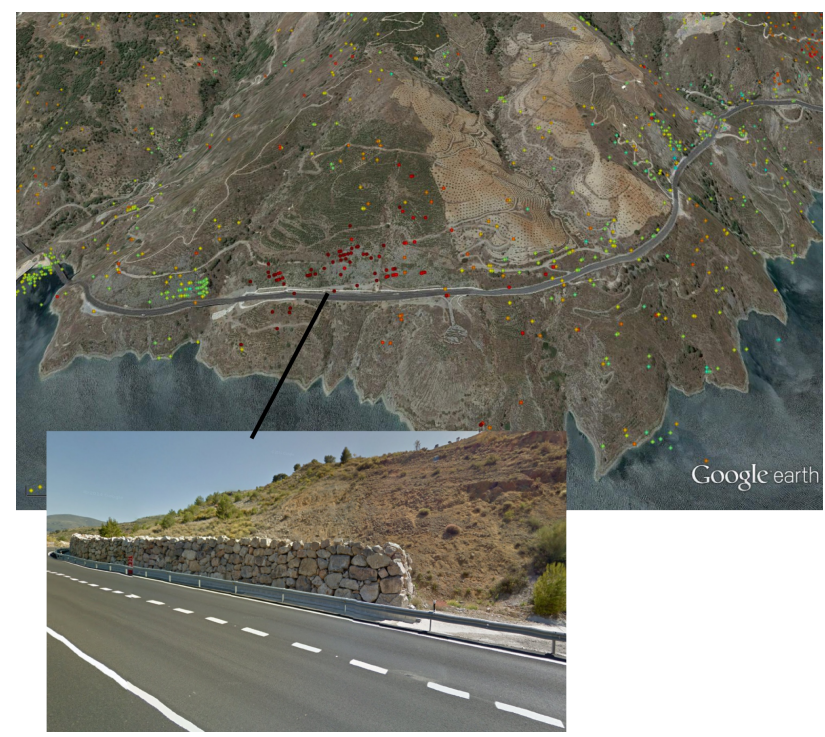

Figure 5. Landslide on the hillside in the Rules reservoir, Spain as detected by PS InSAR processing of Envisat (2002-2009).

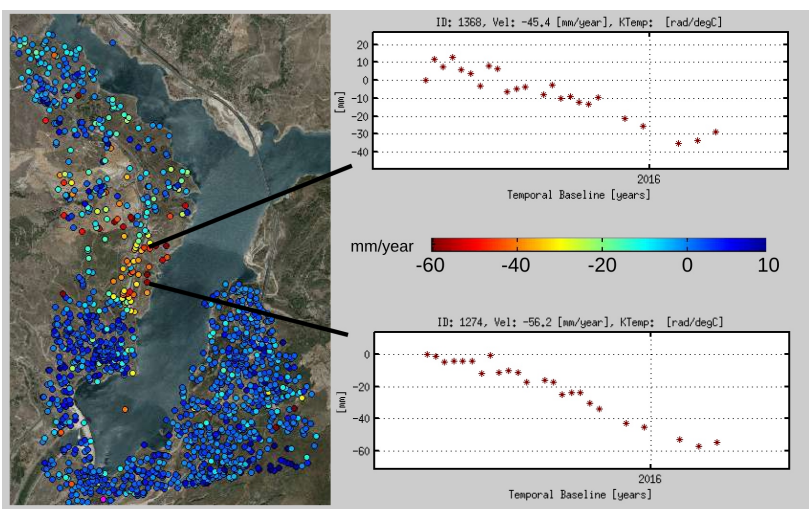

Figure 6. PS InSAR processing result of Rules reservoir area, Spain based on 24 S-1A images from 10/03/2015- 28/03/2016.

\section{IDENTIFICATION OF A SLOPE INSTABILITY FOR LANDSLIDE INVENTORY UPDATES}

Currently InSAR is not used for updating national landslide inventory maps. Especially due to various sources of decorrelation, the reliability of landslide detection from InSAR remains questionable. The high revisit rate of S-1A should tackle the problem of the temporal decorrelation and should increase the reliability of InSAR estimations, at least for slowly 
moving slopes of a moderate extent. The preliminary analyzes described in this section approach towards an identification of a landslide activity. An experimental validation of the qualitative information that can be achieved using S-1 InSAR in this field together with improvements of the briefly introduced techniques in this section is a matter of ongoing investigations.

\subsection{Taskent area, Turkey}

Various types of topographical changes caused local landslides in Taskent area that is located in the southest part of Konya which is one of the biggest city in Turkey (Lat: $36^{\circ} 55^{\prime} 25.63^{\prime \prime N}$, Lon: 32²9'35.19"E). A slope movement causes a local phase change over an interferogram. Assuming no other phase changing factor is present (or has been removed), a slope movement can be evaluated based on a coherence threshold. An example at Fig. 7 (left) presents low coherent areas in a semi-arid region around Taskent town in Turkey based on one S-1 interferogram between $16^{\text {th }}$ November $-10^{\text {th }}$ December 2015 (24 days).

Summing a series of coherence maps, the reliability of the result can be theoretically increased. An advanced masking of vegetation activity should be possible using also cross-polarized S-1 images in the processing chain.
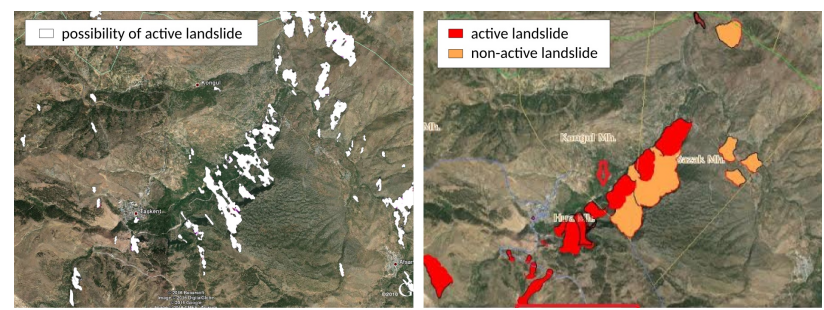

Figure 7. Identification of potentially moving slopes in Taskent town surroundings, Turkey. Left: areas having a coherence of 16/10-10/12/2015 interferogram below given threshold. Right: official landslide inventory (MTA Turkey, 2015).

\subsection{Kolak landslide and surroundings, Turkey}

Kolak is a small village of the Çameli border, Denizli in Turkey (Lat: $37^{\circ} 4^{\prime} 43.24^{\prime \prime N}$, Lon: $\left.29^{\circ} 12^{\prime} 4.97 " E\right)$. A huge landslide damaged buildings in Kolak on $4^{\text {th }}$ February 2015 after an intensive rain episode (Canaslan-Comut, F. et al., 2015b). There has been only $7 \mathrm{~S}-1 \mathrm{~A}$ images available before the landslide event. No slope movements could be reliably interpreted from these images. The signal from three SAR images directly before the landslide event was negatively affected by snow cover and rain.

Kolak is surrounded by landslides. From the InSAR results, it seems that these landslides are very often active, as depicted on Fig. 8 (left) and compared to the official landslide inventory map (right). For this processing, $26 \mathrm{~S}-1 \mathrm{~A}$ images of between $15^{\text {th }}$ October 2014 and $14^{\text {th }}$ January 2016 were combined into 95 spatially filtered interferograms of small temporal and perpendicular baselines. The whole network has been processed using StaMPS SB approach (Hooper, 2008). The resulting LOS mean velocity has been recomputed to values in the direction along the slope based on a basic GIS analysis of SRTM DEM. The result was not properly evaluated until this moment. The movement of Kolak area has been detected as well as areas known to be sliding between Alci and Kolak. However, at this moment the applied detection method cannot be considered reliable enough in practice.
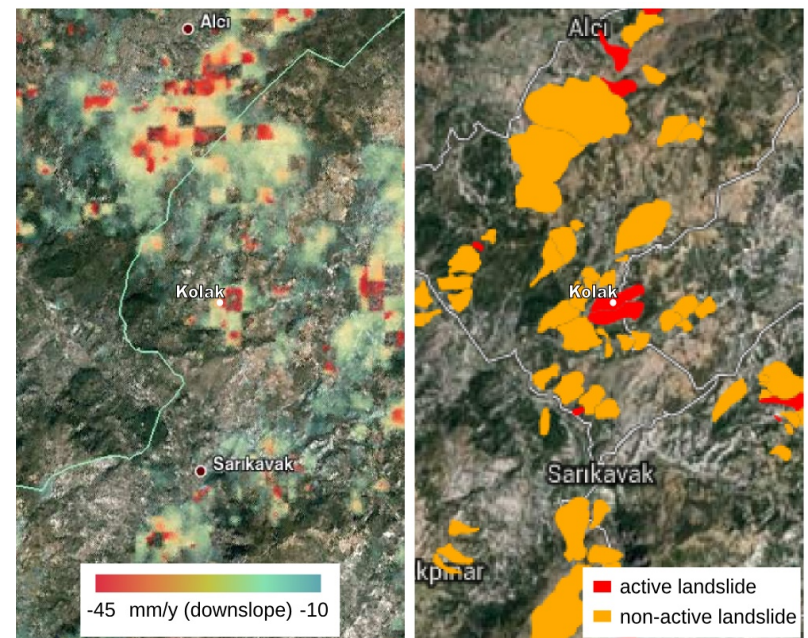

Figure 8. Left: potential landslide activity detected using a basic Sentinel-1 Small Baselines MT-InSAR (based on 26 images between 15/10/2014-14/01/2016). Right: official landslide inventory (MTA Turkey, 2015).

\section{CONCLUSIONS}

Various authors deal with the problem of landslide activity identification from InSAR. The highest motivation for their work was an opportunity to identify first signs of landslide - in such rate that would be normally neglected by other technologies. The pre-sliding signs were not detected in majority of works recognized by the authors, however.

Generally, Sentinel-1A data increases the potential of InSAR for detection of landslides, compared to other C-band SAR data, especially thanks to its high revisit rate. Yet, it is still limited by spatial resolution and its wavelength still does not allow analyzes that would always and reliably detect every landslide event. Using 12-day repeat cycle of Sentinel-1A, the results obtained by individual monitoring methods complement each other and enable better understanding of unstable parts of monitored areas.

The monitoring of existing landslides using satellite radar interferometry on a regular basis can be of a great benefit because it can provide a continuous update of slope movements at a minimum cost. Because InSAR is affected by various error sources, the reliability of a landslide identification differs case by case, depending especially on climatic conditions, applied techniques, acquired data and physical characteristics of the landslide, including orientation of the sliding slope. Obviously, only relatively slow surface changes of a creeping landslide can be detected by the method. Within a proper approach, InSAR should be able to provide a map indicating potentially moving slopes as subjects for a further expertise.

\section{ACKNOWLEDGEMENTS}

This work was supported by The Ministry of Education, Youth and Sports from the National Programme of Sustainability (NPU II) project „IT4Innovations excellence in science LQ1602“ and from the Large Infrastructures for Research, Experimental Development and Innovations project „IT4Innovations National Supercomputing Center LM2015070“. The work has been supported by the Slovak Grant Agency VEGA under projects No. 1/0714/15 and $1 / 0462 / 16$. It was supported also by the project "Detección de zonas de subsidencia en la costa sur peninsular Española 
mediante interferometría radar de satélite (PRX 14/00340) by the Spanish Ministry of Education, Culture and Sport". Sentinel-1A data were provided by ESA under free, full and open data policy adopted for the Copernicus programme. Data have been processed by StaMPS and SARPROZ $^{\circ}$ using Matlab ${ }^{\circledR}$ and Google Maps ${ }^{\mathrm{TM}}$.

\section{REFERENCES}

Abdullaev, U., Abdullaev, S., Blaha, P., Akhmedov, A., Khudobakhshova, G., 2011. The Usoy Dam, Lake Sarez and Possibilities of Geophysical Methods. In: The International Journal on Hydropower \& Dams, HYDRO 2011, Prague, Czech Republic, 9 p. (17-19 Oct. 2011).

Bakon, M., Oliveira, I., Perissin, D., Sousa, J. J. M., Papco, J., 2016. A data mining approach for multivariate outlier detection in heterogeneous 2D point clouds: An application to post-processing of multi-temporal InSAR results. In: Geoscience and Remote Sensing Symposium (IGARSS) 2016, IEEE International, Beijing, China.

Canaslan-Çomut, F., Gurboga, S., Ustun, A., 2015a. Initial results of a surface deformation by using InSAR techniques: Case study of Babadağ (Denizli), Turkey. Surface Models for Geosciences, Vol. 05/2015, chapter 7, pp. 73-86, ISBN: 978-3-319-18406-7, DOI: 10.1007/978-3-319-18407-4_7.

Canaslan-Çomut, F., Durgun, M., Dilmen, H., Onuncuyıl, R., Atilla, Ö. F., 2015b. Geological Survey Report for Çameli Kolak Landslides, Report, AFAD Denizli, Turkey.

Del Ventisette, Ch., Gigli, G., Tofani, V., Lu, P., Casagli, N., 2015. Radar Technologies for Landslide Detection, Monitoring, Early Warning and Emergency Management. In: Modern Technologies for Landslide Monitoring and Prediction, Springer Natural Hazards, Springer-Verlag Berlin, pp. 209-232.

Elashvili, M., Javakhishvili, Z., Godoladze, T., Karakhanyan, A., Sukhishvili, L., Nikolaeva, E., Sokhadze, G., Avanesyan, M., 2012. Historical and paleo events as an input for seismic and associated natural hazard assessment of Javakheti highland (South Georgia).

Gaprindashvili, G. and van Westen, C. J., 2015. Generation of a national landslide hazard and risk map for the country of Georgia. Natural Hazards.

González, P. J., Bagnardi, M., Hooper, A. J., Larsen, Y., Marinkovic, P., Samsonov, S. V., Wright, T. J., 2015. The 2014-2015 eruption of Fogo volcano: Geodetic modeling of Sentinel-1 TOPS interferometry. Geophysical Research Letters, 42(21), pp. 9239-9246.

Gracheva, R., Golyeva, A., 2010. Landslides in mountain regions: hazards, resources and information. In: Geophysical Hazards, International Year of Planet Earth, Springer Dordrecht, Netherlands, pp. 249-260.

Grandin, R., Klein, E., Métois, M., Vigny, C., 2016. Three-dimensional displacement field of the 2015 Mw8.3 Illapel earthquake (Chile) from across-and along-track Sentinel-1 TOPS interferometry. Geophysical Research Letters.

Guzzetti, F. Mondini, A. C., Cardinali, M., Fiorucci, F., Santagelo, M., Chang, K-T., 2012. Landslide inventory maps: New tools for an old problem. Earth-Science Reviews, 112 (1-2), pp. 42-66.
Hooper, A., 2008. A multi-temporal InSAR method incorporating both persistent scatterer and small baseline approaches. Geophysical Research Letters, 35 (16).

Jibson, R. W., Prentice, C. S., Borissoff, B. A., Rogozhin, E. A., Langer, C. J., 1994. Some observations of landslides triggered by the 29 April 1991 Racha earthquake, Republic of Georgia. Bull. Seismol. Soc. Am., 84(4), pp. 963-973.

Jung, H. S., Lu, Z., Zhang, L., 2013. Feasibility of Along-Track Displacement Measurement From Sentinel-1 Interferometric Wide-Swath Mode. IEEE Transactions on Geoscience and Remote Sensing, 51(1), pp. 573-578.

Lazecký, M., Canaslan-Çomut, F., Hlaváčová, I., Gürboğa, Ş., 2015. Practical applicability of satellite-based SAR interferometry for detection of landslide activity. In: Procedia Earth and Planetary Science WMESS 2015, Prague, Czech Republic, 10 p. (7-11 Sep. 2015).

Macciotta, R., Hendry, M., Derek Martin, C., 2016. Developing an early warning system for a very slow landslide based on displacement monitoring. Natural Hazards, 81(2), pp 887-907. doi: 10.1007/s11069-015-2110-2.

Malgot, M., Baliak, F., Mahr, T., 1983. Map of Vtacnik slope failures 1:10 000. Slovak cartography.

MTA Turkey, 2015. Geoscience Map Viewer and Drawing Editor. General Directorate of Mineral Research and Exploration - The Department of Scientific Documentation and Publicity. URL: http://yerbilimleri.mta.gov.tr/anasayfa.aspx .

Nikolaeva, E., Walter, T. R., 2012. Comparison of InSAR two-pass and time series methods for analysing landslides in central Georgia, Caucasus. In: IEEE International Geoscience and Remote Sensing Symposium 2012, pp. 7573-7576.

Nikolaeva, E., Walter, T. R., 2013. Integration of InSAR results from TerraSAR-X with ALOS(PALSAR) data for the landslide area, case study from Sachkhere region, Georgia.

Nikolaeva, E., Walter, T. R., Shirzaei, M., Zschau, J., 2013. Landslide dynamics and coupling revealed by L-band InSAR in central Georgia. Natural Hazards Earth Syst. Sci. Discuss., 1(5), pp. 4925-4962.

Novellino, A., Cigna, F., Sowter, A., Syafiudin, M. F., Di Martire, D., Ramondini, M., Calcaterra, D., 2015. Intermittent Small Baseline Subset (ISBAS) InSAR analysis to monitor landslides in Costa Della Gaveta, Southern Italy. In: IEEE Geoscience and Remote Sensing Symposium (IGARSS) 2015, pp. 3536-3539, doi: 10.1109/IGARSS.2015.7326584.

Perissin, D., Rocca, F., Wang, T., 2007. DEM Retrieval and Landslide Monitoring in Badong, Three Gorges, China by Means of InSAR Partially Coherent Targets. In: Proceedings of Dragon Symposium 2007, Aix En Provence, France.

Polcari, M., Palano, M., Fernández Torres, J., Samsonov, S., Stramondo, S., Zerbini, S., 2016. 3D displacement field retrieved by integrating Sentinel-1 InSAR and GPS data: the 2014 South Napa earthquake.

Samieie-Esfahany, S., Hanssen, R. F., van Thienen-Visser, K., Muntendam-Bos, A., 2009. On the Effect of Horizontal Deformation on InSAR Subsidence Estimates. In: Proceedings of The Fringe 2009 Workshop, Frascati, Italy, Vol. 30. 
Scaioni, M., Longoni, L., Melillo, V., Papini, M., 2014. Remote Sensing for Landslide Investigations: An Overview of Recent Achievements and Perspectives, Remote Sensing, 6(1-x), 53 p.

Sun, Q., Zhang, L., Ding, X.L., Hu, J., Li, Z. W., Zhu, J. J., 2015. Slope deformation prior to Zhouqu, China landslide from InSAR time series analysis. Remote Sensing of Environment, 156, pp. 45-57, doi: 10.1016/j.rse.2014.09.029.

van Westen, C. J., Straatsma, M. W., Turdukulov, U. D., Feringa, W. F., Sijmons, K., Bakhtadze, K., Janelidze, T., Kheladze, N., Natsvlishvili, L., Tkhelidze, N., Gaprindashvili, G., Megrelidze, I., Geladze, G., Gloveli, V., Sukhishvili, L. Elashvili, M., Tsamalashvili, T., Feliciano, I. T., 2012. Atlas of Natural Hazards and Risk in Georgia. CENN Caucasus Environmental NGO Network.

Vöge, M., Frauenfelder, R., Ekseth, K., Arora, M.K., Bhattacharya, A., Bhasin, R.K., 2015. The use of SAR Interferometry for landslide mapping in the Indian Himalayas. In: The International Archives of the Photogrammetry, Remote Sensing and Spatial Information Sciences, 36th International Symposium on Remote Sensing of Environment, Vol. XL-7/W3, Berlin, Germany (11-15 May 2015), doi:10.5194/isprsarchives-XL-7-W3-857-2015.

Wen, Y., Xu, C., Liu, Y., Jiang, G., 2016. Deformation and Source Parameters of the $2015 \mathrm{Mw} 6.5$ Earthquake in Pishan, Western China, from Sentinel-1A and ALOS-2 Data. Remote Sensing, 8(2), pp. 134.

Xue, Y., Li, K., Meng, X., Guo, P., WasowskI, J., Bovenga, F., Zeng, R., Chen, G., 2016. Spatial analysis of surface deformation distribution detected by persistent scatterer interferometry in Lanzhou Region, China. Environmental Earth Sciences, pp. 75-80, doi: 10.1007/s12665-015-4806-8. 